\title{
A Device-Based Process Signal Design of Electric Power Plants
}

\author{
Juraj Simunic ${ }^{1}$, Mirko Randic ${ }^{2}$, Marijana Zivic ${ }^{3}$ \\ ${ }^{1}$ Technical faculty, University of Rijeka, Rijeka, Croatia \\ ${ }^{2}$ Faculty of Electrical Engineering and Computing, University of Zagreb, Zagreb, Croatia \\ ${ }^{3}$ Technical faculty, University of Rijeka, Rijeka, Croatia
}

\begin{abstract}
Automation and computerized control of processes in electric power plants were intensively started at the end of seventies and at the beginning of eighties during the introduction of microprocessor-based computer systems. The first generation of the information processing equipment has in most cases already become disused. From that time, visibility of controlled process has been increased by installing new and modern devices which enable better informing about all relevant events. The increased quantity of information by which processes can be described implies that new and more efficient techniques for information modeling should be developed.
\end{abstract}

In this paper a device-based approach to process information modeling is proposed. Such modeling approach is more efficient than function-based approach we used before. The efficiency lies in the fact that device-based approach is in the very essence an object-oriented modeling approach. Therefore, device-based information models can be easily mapped to object-oriented models. Both function-based and device-based modeling approaches are described in the paper and differences between two modeling paradigms are emphasized. In the last Chapter of the paper analogy between device-based and object-oriented models is described. This analogy represents basis for the model mapping.

Keywords: electric power plant, information modeling, process signal base, device-based model, object-oriented model

\section{Introduction}

The starting point for electric power plant (EPP) modeling for the needs of building an attached building and maintenance of the automation and control system is a process information modeling. Structure of information and information flows between the controlled power plant and control system must be known. Determination of the data and signals structure of the information flows is a very complicated task even for small EPPs.

There are problems arising out of:

- equipment diversity used in EPPs;

- complexity of technological process in controlled systems, which surpasses knowledge of a single person and thus sets up an imperative to organize a group of people (experts) for a particular part of the process technology;

- a relatively great number of signals which interchange between controlled and control systems;

- a need for good expertness in concrete EPP and its specific qualities.

In Chapter 2 of the paper, the function-based modeling of process signals is presented. Such modeling approach is technology-dependent, and now we are treating it as an obsolete approach. Nevertheless, a short description of the approach is included here because devicebased approach is partly based on it. Thus, a reader can consider the evolution of our modeling paradigm more easily. The function-based approach has been used for information modeling of processes in EPPs during the years of our projects [8]. In Chapter 3, methodology for process signal design based on devices as basic element of each EPPs is presented. Devicebased modeling approach is focused on identification of devices by their location in EPP and assigning signals to each device type. By the paradigm, the process signal structure of 


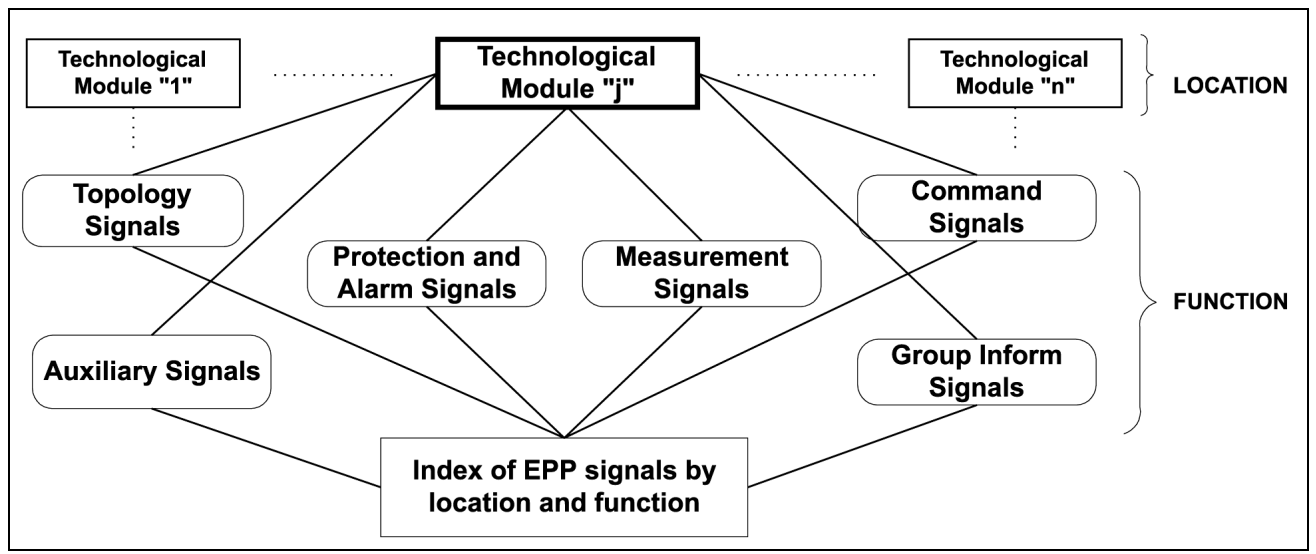

Fig. 1. Function-based EPP process signal model.

the observed EPP is obtained in a modular and optimal way. Besides, it is underlined in Chapter 4 that the described devices-based modeling fits into modern object-oriented modeling approach. How the device-based model could be mapped into object-oriented model is also explained in this chapter.

\section{Function-Based Process Signal Model}

The function-based process signal model represents the first generation process signal design, which originates from the beginning of the eighties. It is based on the technological modules of an EPP, along with signals by their function in the EPP process (Figure 1). By such a model, EPP process signals are defined according to their location (particular technological module in the EPP) and function i.e. signal function in the EPP operation description. Technological modules are considered as sources and sinks of signals, and signals are categorized by their function. In the model, function-technological module (FTM) is used as a base for signal structure definition. The generator commands or transformer alarm signals are examples of the FTMs (Table 1).

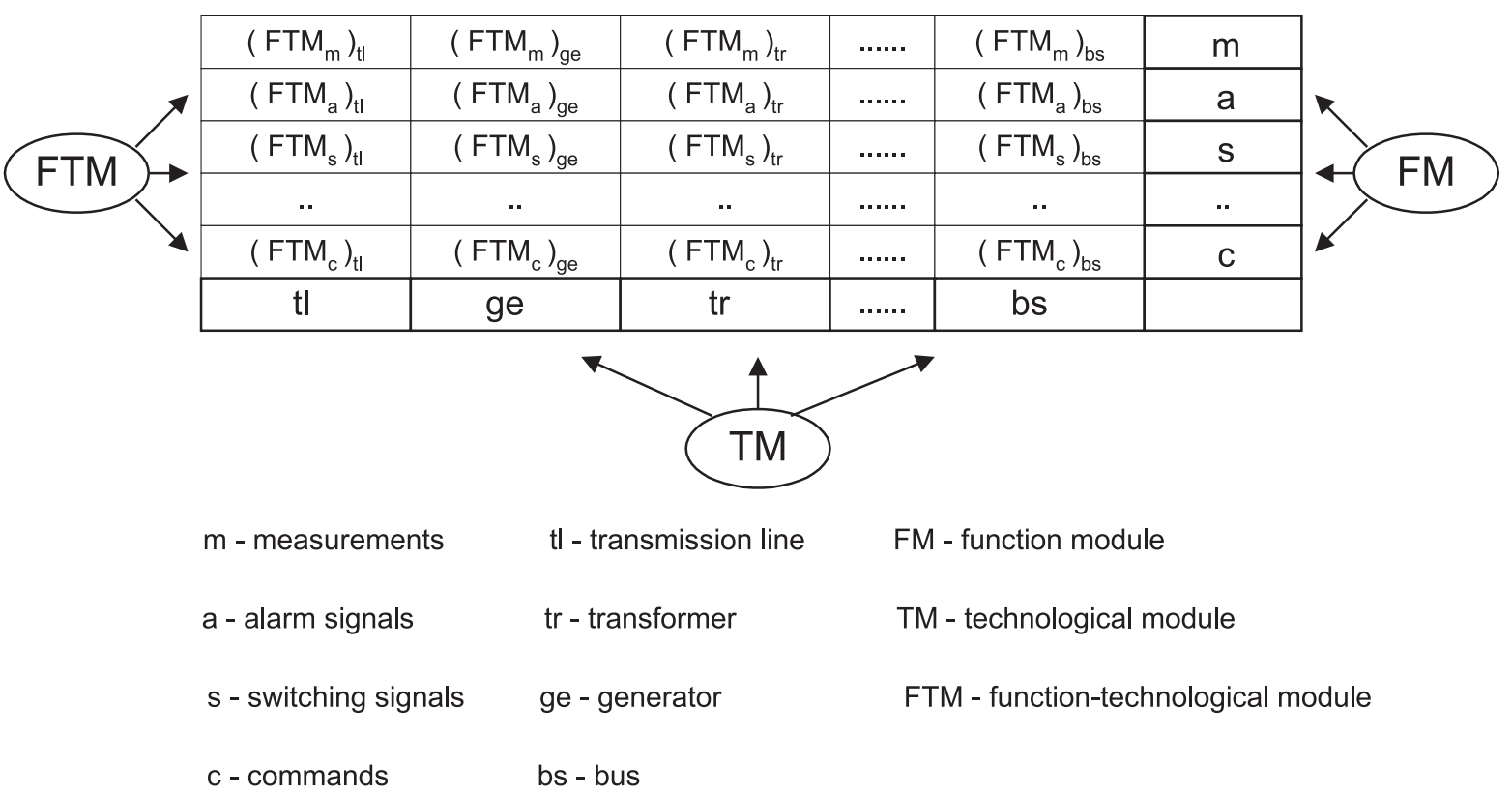

Table 1. Function-technological modules. 
By introducing the third aspect of a signal the signal value, the corresponding EPP signal structure is defined as a three-dimensional vector (Figure 2).

The set of signals $S_{F T}$ on the level of an EPP for all technological modules and for all types of signals can be defined as:

$$
\begin{aligned}
S_{F T}=\left\{\alpha_{x y z}\right\} \quad x & =1,2,3, \ldots, m \\
y & =1,2,3, \ldots, n \\
z & =0,1,2, \ldots, r,
\end{aligned}
$$

where $\alpha_{x y z}$ presents the signal defined by function $x$, location $y$ and value $z$. The signal subset $S_{x}$ represents all signals of one FM from all technological modules of an EPP. It can be defined by the equation (1) with $x=$ cons. $y z$-plane in Figure 2 relates to this subset. The signal subset $S_{y}$ represents all signals of all FM from one technological module of an EPP. It can also be defined by the equation (1) with $y=$ cons. (xz-plane from Figure 2). Finally, the subset $S_{x y}$ (FTM) depicts all signals from one technological module and for one signal quality i. e. function. It can also be defined by the equation (1), but with $x=$ cons. and $y=$ cons.

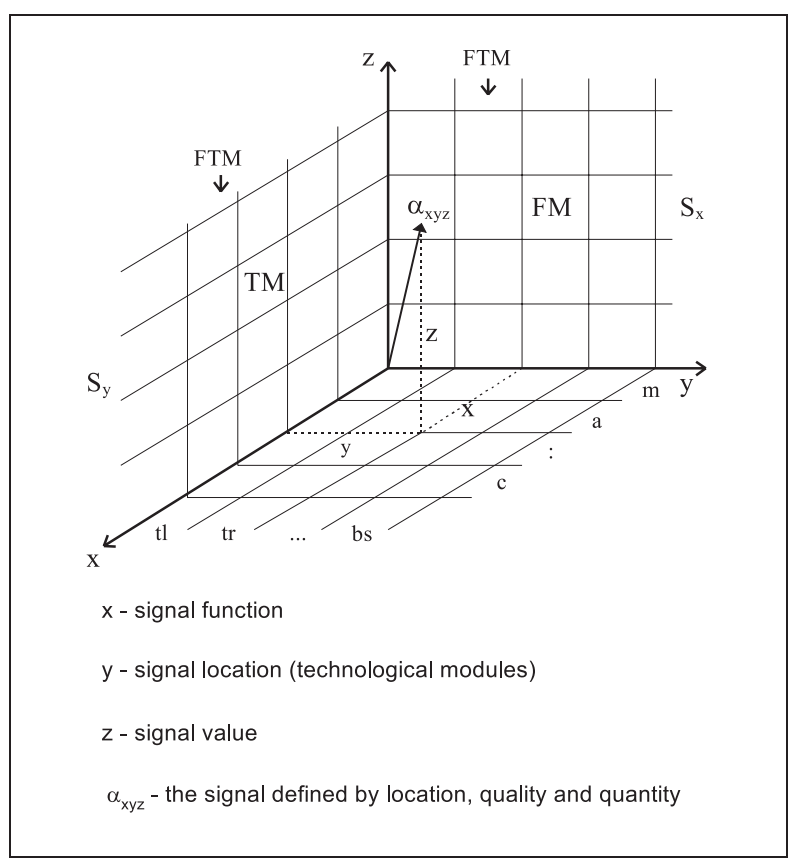

Fig. 2. EPP signal representation by vector.

Model of process signal structure organized in the above-mentioned way and defined at the level of an EPP, can be used for EPP operation analysis and for estimation of various information flows. However, it has some specific limitations and drawbacks, as follows:

- Process signals are organized at the level of technological modules in EPP, the complete procedure has to be repeated for each EPP. The model is not independent of the EPP. Moreover, modular design is not possible.

- Device, as a basic EPP component, is not separated as an information bearing unit.

- Device states cannot be defined for the needs of a modern process signal design, and the links among devices cannot be determined either.

- Redundancy of the data entry is significantly greater.

As an example, one part of process signal base generated by function-based modeling approach is presented in Table 2. The records are extended with additional data-encoded parameter and with the denoted places for signal usage (third column - REPORTS). The first column denotes the signal function; signals are grouped according to their function. The second column represents signal value and the signal code. In the third column, locations for sending signals or location within the EPP or in master substation (MS) are marked. Reports can be obtained from event list (E), alarm list (A), fault list $(\mathrm{F})$, chronological event list (CEL), single line scheme (SLS), cabinet (C) and synoptic chart (SP).

Three-dimensional signal encoding is based on the following principle:

- the first group of digits ( $y$ dimension from the model) is divided into three subgroups:

- the first subgroup consists of two digits and it marks the bay (01 - Feeder bay, 02 - Link bay,... );

- the second subgroup consists of one digit and denotes voltage level of the observed bay $(1-110 \mathrm{kV}, 2-220 \mathrm{kV}, 3-35 \mathrm{kV})$;

- the third subgroup is made up of two digits and marks the bay name (01 - Melina 1,02 - Melina 2,...), it is used if there are more bays of the same kind. 


\begin{tabular}{|c|c|c|c|c|c|c|c|c|c|c|c|}
\hline \multicolumn{12}{|c|}{ 220kV LINK BAY } \\
\hline \multirow{3}{*}{ FUN } & \multirow{3}{*}{\multicolumn{3}{|c|}{ SIGNAL VALUE (NAME) AND CODE }} & \multicolumn{8}{|c|}{ REPORTS } \\
\hline & & & & \multicolumn{6}{|c|}{ MS } & \multicolumn{2}{|c|}{ EPP } \\
\hline & & & & $\mathrm{E}$ & A & $\mathrm{F}$ & CEL & SLS & SP & CEL & $\mathrm{C}$ \\
\hline \multirow{6}{*}{$\begin{array}{c}\mathrm{c} \\
\mathrm{o} \\
\mathrm{m} .\end{array}$} & Feeder & connect & 022003 & & & & + & & & + & + \\
\hline & Feeder & disconnect & 022003 & & & & + & & & + & + \\
\hline & Feeder & connect & 022003 & & & & + & & & + & + \\
\hline & Feeder & disconnect & 022003 & & & & + & + & + & & \\
\hline & Circuit Breaker & connect & 022003 & & & & + & & & + & + \\
\hline & Circuit Breaker & disconnect & 022003 & & & & + & + & + & & \\
\hline \multirow{3}{*}{$\begin{array}{l}\mathrm{s} \\
\mathrm{i} \\
\mathrm{g} .\end{array}$} & Feeder & connected & 022004 & + & & & + & + & + & + & \\
\hline & Feeder & disconnected & 022004 & + & & & + & + & + & + & \\
\hline & Feeder & intermediate & 022004 & + & + & + & + & + & + & + & \\
\hline \multirow{9}{*}{$\begin{array}{l}\mathrm{t} \\
\mathrm{o} \\
\mathrm{p} \\
\mathrm{o} \\
1 \\
\mathrm{o} \\
\mathrm{g} \\
\mathrm{y}\end{array}$} & Feeder & failure & 022004 & + & + & + & + & + & + & + & \\
\hline & Feeder & connected & 022004 & + & & & + & + & + & + & \\
\hline & Feeder & disconnected & 022004 & + & & & + & + & + & + & \\
\hline & Feeder & intermediate & 022004 & + & + & + & + & + & + & + & \\
\hline & Feeder & failure & 022004 & + & + & + & + & + & + & + & \\
\hline & Circuit Breaker & connected & 022004 & + & & & + & + & + & + & \\
\hline & Circuit Breaker & diconnected & 022004 & + & & & + & + & + & + & \\
\hline & Circuit Breaker & intermediate & 022004 & + & + & + & + & + & + & + & \\
\hline & Circuit Breaker & failure & 022004 & + & + & + & + & + & + & + & \\
\hline \multirow{6}{*}{$\begin{array}{l}\mathrm{p} \\
\mathrm{r} \\
\mathrm{o} \\
\mathrm{t} \\
\mathrm{e} \\
\mathrm{c} .\end{array}$} & $>$ I Protection & connected + & 022001 & & & & + & & & + & + \\
\hline & $>$ I Protection & connected - & & & & & + & + & + & & \\
\hline & $<$ I Protection & diconnected + & 022001 & & & & + & & & + & + \\
\hline & $<$ I Protection & connected - & & & & & + & + & + & & \\
\hline & Busbar Protection & diconnected + & 022001 & & & & + & & & + & + \\
\hline & Busbar Protection & diconnected - & & & & & + & + & + & & \\
\hline \multirow{8}{*}{$\begin{array}{c}\mathrm{a} \\
\mathrm{l} \\
\mathrm{a} \\
\mathrm{r} \\
\mathrm{m}\end{array}$} & Circuit Breaker & Air $<16 \mathrm{~B}+$ & 022002 & & & & + & & & + & \\
\hline & Circuit Breaker & Air $<16 \mathrm{~B}-$ & & & & & + & & & + & \\
\hline & Circuit Breaker & Air $<14 \mathrm{~B}+$ & 022002 & & & & + & & & + & \\
\hline & Circuit Breaker & Air $<14 \mathrm{~B}-$ & & & & & + & & & + & \\
\hline & Circuit Breaker & Air $<11 \mathrm{~B}+$ & 022002 & & & & + & & & + & \\
\hline & Circuit Breaker & Air $<11 \mathrm{~B}-$ & & & & & + & & & + & \\
\hline & $220 \mathrm{~V}=\mathrm{UP} / \mathrm{SIG}$ & failure + & 022002 & & & & + & & & + & \\
\hline & $220 \mathrm{~V}=\mathrm{UP} / \mathrm{SIG}$ & failure - & & & & & + & & & + & \\
\hline
\end{tabular}

Table 2. Process signals characterized by their function (extracted from the signal base).

- the second group (one digit) determines qualities of the signal ( $x$ dimension from the model), i. e. divides the signals by their function. They can be: 1 - protection signals, 2 - alarm signals, 3 - commands, 4 - state signals, 5 - measuring signals, 6 - regulation signals, 7 - other signals, 8 - group signals.

- the third group (composed of three digits) defines the signal value $(z$ dimension from the model).

\section{Device-Based Process Signal Model}

Our new approach to designing the process signal base is based on the device as the main information bearing and organizational unit [3], [6], [9]. There are three steps in the design:

1. Signal structure systematization by device types (determination of signals generated or received by devices of particular type) 
2. EPP analysis by means of the technological module (decomposition of an EPP into disjunct modules and making associations between devices and the modules).

3. Determination of the signal usage (locations of particular signal usage).

With the new design approach, some new concepts necessary for the model description have come up. The concepts (variable, variable value, signal by device type and signal by EPP) are described in the following sections (from 3.1. to 3.3$)$.

\subsection{Signal Structure Systematization by Device Type}

Signal structure systematization represents the core of the EPPs process information model. The term signal structure systematization comprehends (Figure 3):

- identification of various device types,

- information analysis of the device types (identification variables and their possible values),

- definition of signal structure.

The device type identification points up and considers all devices in the EPPs which in any way represent the signal source or sink, and which give us an insight into the state of the controlled process. A device can be observed as an abstraction of the technical device without regard to function of that technical device in the particular EPP, but with regard to information characteristics by which the EPP operation is described. Devices are modeled regardless of the question whether they are used in several different places in the EPP. Also, the operation fields of these devices have not been taken into account. Such a model represents a device type. In Table 3, a part of device type list is presented.

\begin{tabular}{||c|c||}
\hline \hline Code & Device Type \\
\hline \hline 1. & feeder disconnector \\
\hline 2. & feeder MV disconnector \\
\hline & $\cdots$ \\
\hline 7. & circuit breaker $\mathrm{SF}_{6}$ \\
\hline 8. & oil breaker \\
\hline & $\cdots$ \\
\hline 14. & differential relay \\
\hline 15. & relay I $>$ protection \\
\hline & $\cdots$ \\
\hline \hline
\end{tabular}

Table 3. Device type list.

After the device types identification, variables which describe device operation have to be defined. In Figure 4 the device type and the variables pertaining to this type are presented. The variable is a quantity that may assume any given value by which we can describe the device operation in EPP. At a particular point of time, a value is assigned to the variable and they together make up a signal. The device type is determined by at least one variable, but depending on the operational complexity of the device it can have more than one.

Each variable is defined by at least two values. The device, i. e. the variable cannot be defined by only one variable value, because it means that the device doesn't change its state. The devices, which do not change or cannot change their state do not have to be controlled. Variable values are given for the specific variable

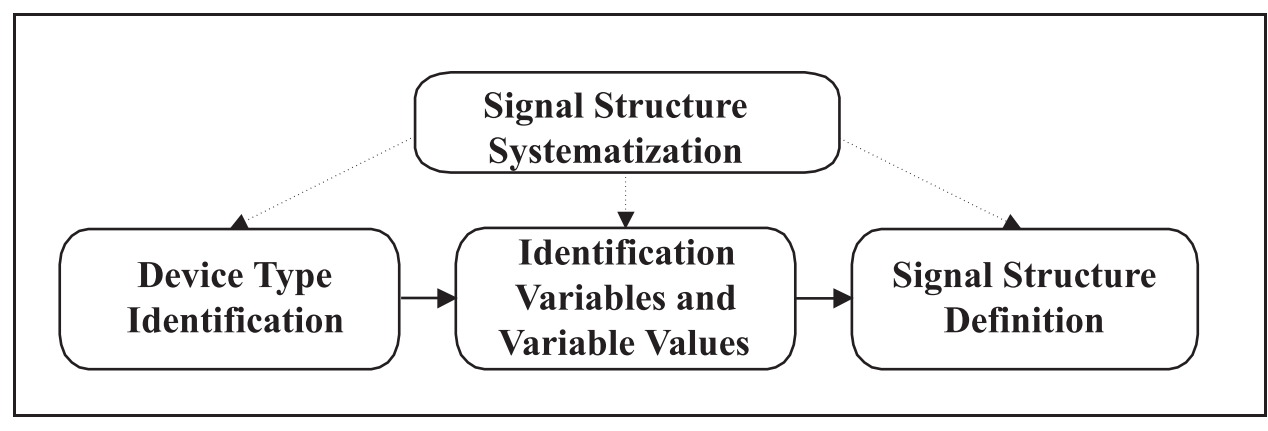

Fig. 3. Signal structure systematization. 


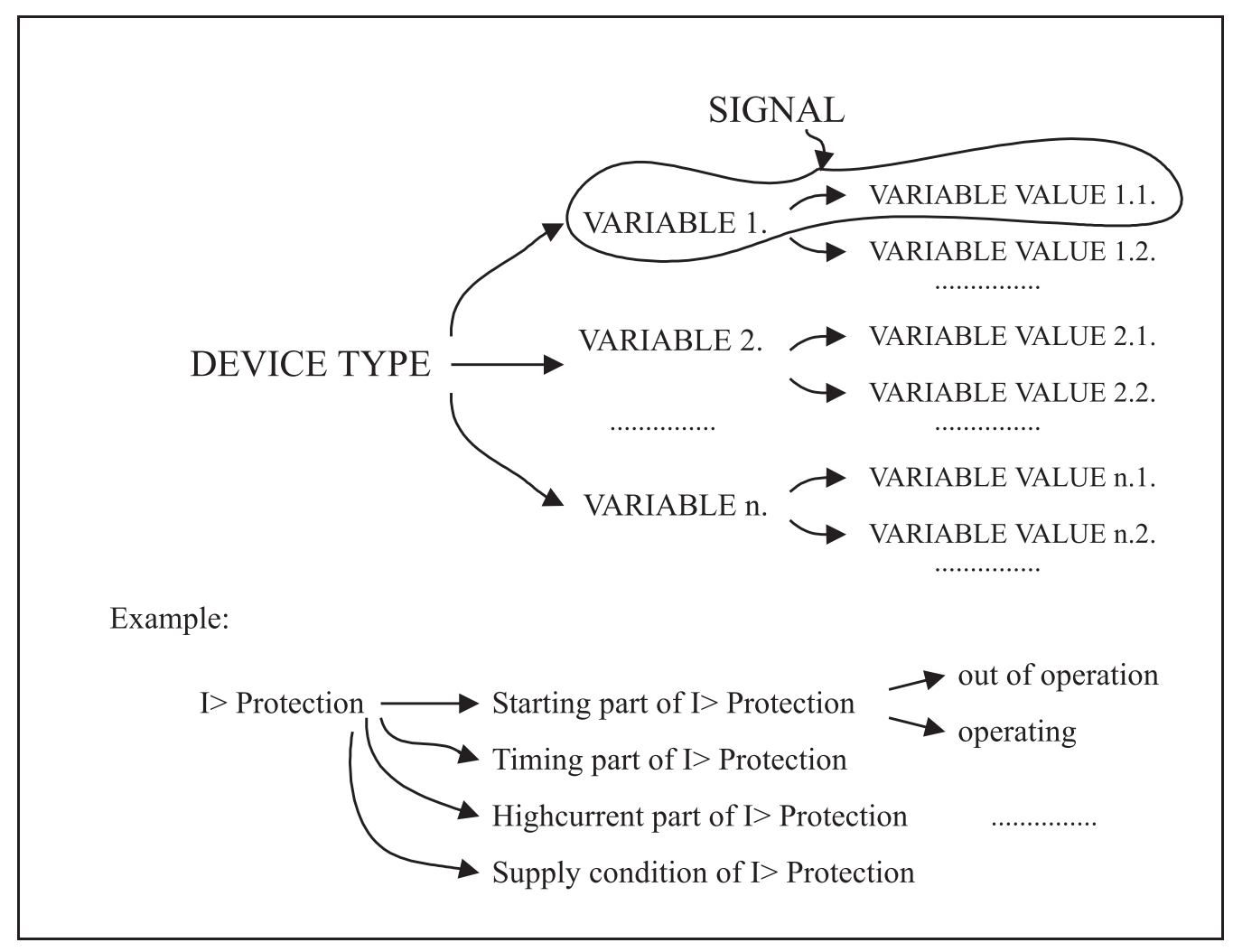

Fig. 4. The device type, its variables and variable values.

in operation. By them, the device states are defined. The variable can be described by two or more values.

The arranged couple $[($ variable $)+($ variable values)] form a signal. Thus, the signal is defined as a quantity made up of the variable name with values pertaining to it. Schematic presentation of a device type with associated signals is presented in Figure 5. The group of signals represents a static set of all possible signals by which operation of the device type is described.

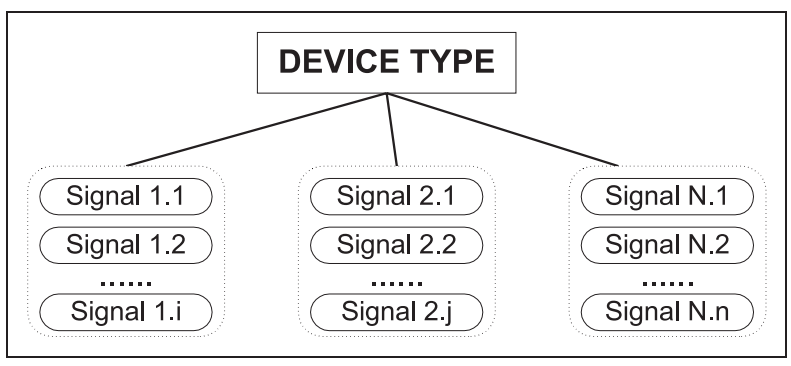

Fig. 5.A schematic presentation of the device type with associated signals.

An example of device types with associated signals is presented in Table 4. The content of the table is formed as follows:

- the first column of the table contains ordinal codes of each device type, which can be used in data processing;

- the second column of the table, contains the device type identification;

- the third column contains signals formed by variable name and variable values.

From the list presented in Table 4, it is possible to derive the set of static signals by device types. An example of such a set of static signals is presented in Figure 6.

The set of static signals per device types is created independently of any particular kind of EPPs. So, its subsets could be applied to hydroelectric power plants, thermo-electric power plants, transmission and distribution electric power systems. Furthermore, signal structure can be presented in a 3D coordinate system as a vector according to Figure 7. Device types are marked on the $x$ axis, variable names on $y$ and variable values on the $z$ axis. 


\begin{tabular}{|c|c|c|c|}
\hline \multicolumn{4}{|c|}{ Set of Signals by Device Types } \\
\hline \multirow{2}{*}{$\operatorname{cod}$} & \multirow{2}{*}{ device type } & \multicolumn{2}{|l|}{ signals } \\
\hline & & variable name & variable values \\
\hline \multirow[t]{2}{*}{1} & \multirow[t]{2}{*}{ feeder disconnector } & feeder disconnector - command & $\begin{array}{l}\text { connect } \\
\text { disconnect }\end{array}$ \\
\hline & & feeder disconnector & $\begin{array}{l}\text { connected } \\
\text { disconnected } \\
\text { intermediate position } \\
\text { failure }\end{array}$ \\
\hline & & $\cdots$ & \\
\hline \multirow[t]{4}{*}{15} & \multirow[t]{4}{*}{ I $>$ protection } & starting part of I $>$ protection & $\begin{array}{l}\text { OK } \\
\text { operating }\end{array}$ \\
\hline & & supply condition of I> protection & $\begin{array}{l}\text { OK } \\
\text { loss }\end{array}$ \\
\hline & & timing part of $\mathrm{I}>$ protection & $\begin{array}{l}\text { OK } \\
\text { operating }\end{array}$ \\
\hline & & high current part of I $>$ protection & $\begin{array}{l}\text { OK } \\
\text { operating }\end{array}$ \\
\hline
\end{tabular}

Table 4. Device types with associated signals.

By observing Figure 7. we can take into consideration the following organized sets of signals:

- Set of all process signals by device types $S_{D}$ is defined by points of the $x y z$ space i. e. by expression:

$$
\begin{aligned}
S_{D}=\left\{\sigma_{x y z}\right\} \quad x & =1,2, \ldots, m \\
y & =1,2, \ldots, n \\
z & =0,1, \ldots, r,
\end{aligned}
$$

where $\sigma_{x y z}$ presents the signal defined by device type, variable and variable values, where $m$ is the number of device types, $n$ is

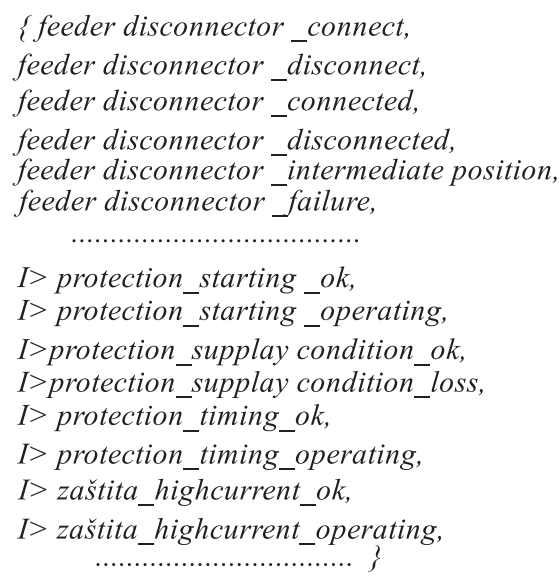

Fig. 6.Part of the static signal set. the number of variables and $r$ is the number of variable values of every existing variable.

- The set of signals of one device type is defined on $y z$-plane, i. e. by equation (2), with $x=$ cons.

- The set of signals of one variable is defined on $x z$-plane, i. e. by equation (2), with $y=$ cons.

- The points on the axis parallel with $z$ represent the signals of one variable and one

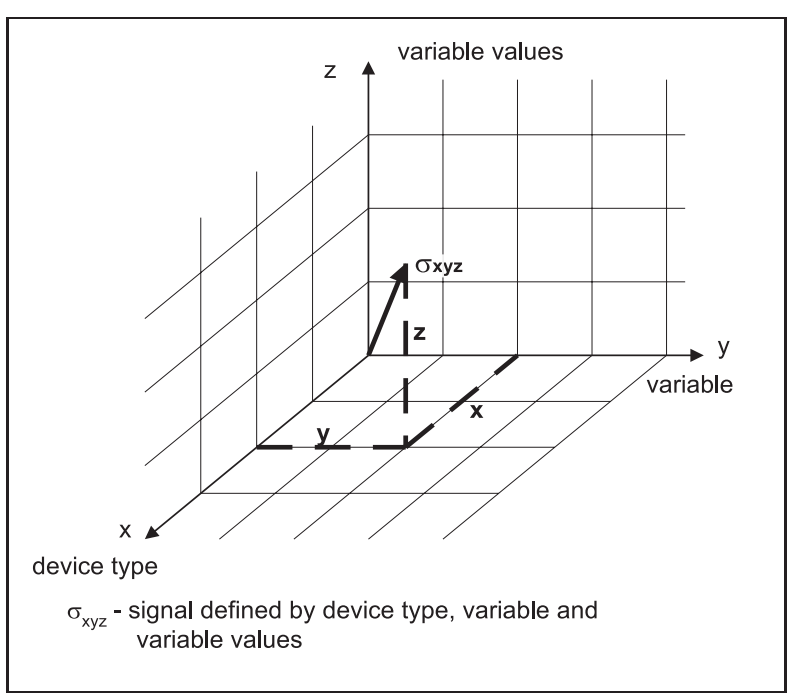

Fig. 7.Vector presentation of the device-based signals. 
device type. The subset can also be defined by equation (2), but with $x=$ cons. and $y=$ cons.

- Finally, the subset of points on the $x y$-plane represent the set of all variables per devices. This variable set, each for itself defines one signal and is presented by equation (2) with $z=$ cons.

According to circumstances and application of such a model, one can define other characteristic sets of process signals. Comparing equation (2) and related equations with equation (1) and its related equations, which are used in describing the device-based and the function-based models, the following may be concluded:

- Formally, the structural frame of expressions of particular process signal sets i. e. sets $S_{F T}$ and $S_{D}$ is entirely analogue.

- In essence, $S_{F T}$ and $S_{D}$ sets represent completely different process signal sets and enable different approaches to process signal design.

- The $S_{F T}$ sets are strictly tied with the technology of a particular EPP and cannot be directly applied to other EPPs.

- Device-based process signal sets $S_{D}$ are generic (technology-independent) and open designed and they can be universally applied to a great array of EPPs.

- Process signals of device-based design represent technology-independent data base of signals which can be easily expanded with new signals.

\subsection{Technological Decomposition of an EPP}

The first requirement in scope of information modeling is defining a device type model. The model is described in 3.1. The second requirement is defining an EPP model. That model should allow unambiguous device identification on the base of its location in EPP. In the model, device systematization by location follows technological structure of an EPP.

Because even a small EPP is too complex a system to embrace its overall operation at once, internal functioning of its subsystems should be described. Therefore, the model construction begins at the level of subsystems. Subsystems have to be built according to the following principles:

- the borders between subsystems and ways of their interaction at these borders have to be determined;

- a subsystem has to be rather simple for the internal operation description;

- subsystems mustn't overlap;

- the whole modeled system has to be constructed by combining all its subsystems.

To satisfy the condition that the subsystems mustn't overlap, we introduce the following concepts: technological unit, technological field, technological modules and technological submodules.

- Technological unit is a group of devices in the EPP that performs some complex function (command room, engine room).

- Technological field is a part of a technological unit where voltage levels $(400 \mathrm{kV}, 220$ $\mathrm{kV}, 110 \mathrm{kV}, 35 \mathrm{kV}$, etc.) are separated.

- Technological modules are made by separating the technological field by lines $(220$ $\mathrm{kV}$ feeder bay Melina,...). If necessary, technological submodules can be obtained by further separating the technological module.

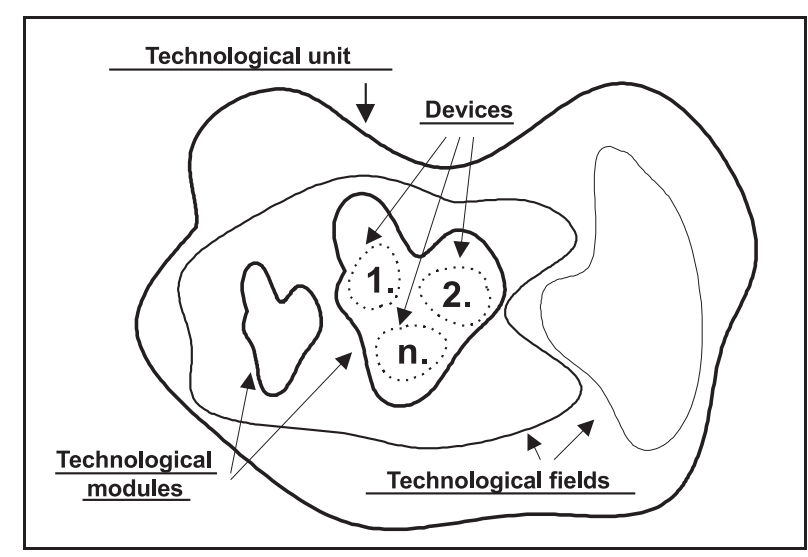

Fig. 8. Tehnological decomposition of an EPP.

Figure 8. illustrates division of one part of an EPP (a technological unit) into technological fields, technological modules and devices. Determination of the technological fields i.e. modules is a problem of EPP modeling. If chosen 
technological modules are too narrow, there will be a great number of them, they will overlap and will not function as qualitative EPP modeling. On the other hand, if chosen technological modules are too wide, then it is possible that the signal will not be precisely defined and located, especially if there are a number of devices of the same type in one technological module. Eventually, in such a situation we have to create new, smaller submodules within the very technological module which could enable unambiguous definition of signals.

Now, it is possible to explain the procedure for generating a set of static process signals for a particular EPP. The signal set generating procedure is based on the presented information model of EPP and is supported by a computer. First, we have to identify the technological units, fields and modules in the observed EPP. Then, we associate devices with those pertaining technological modules. When we associate devices with technological modules, we actually say that technological modules are "filled with devices". Table 5. presents the principle how to associate devices to single technological modules.

Because every device has its own type, signals that a device can send (receive) correspond to the signals of that particular type. The procedure for generating a set of static signals per EPP is presented in Figure 9, and the printout of the set of signals per EPP is presented in Table 6.

\subsection{Signal Usage Location}

After the set of static signals per EPP is generated, signal usage location has to be determined. If we consider, for instance, a hydroelectric power plant as an EPP, the plant would be basically divided into the following technological units: control room, engine room and water power supply. Signal usage locations within a control room would be: control board $(\mathrm{CB})$, relay board (RB) and auxiliary switchboard (AS). Signal usage locations in the engine room are: engine board (EB), engine auxiliary switchboard (EA), actuator board (AB),

\begin{tabular}{|c|c|c||}
\hline \hline code & technological modules & associated device (coded) \\
\hline \hline 9 & $220 \mathrm{kV}$ Feeder Bay Melina & $1,3,7,32,33,34,36,37,38,64,74,94,97,111,123,125$ \\
\hline
\end{tabular}

Table 5. The principle of association of the devices to technological modules.

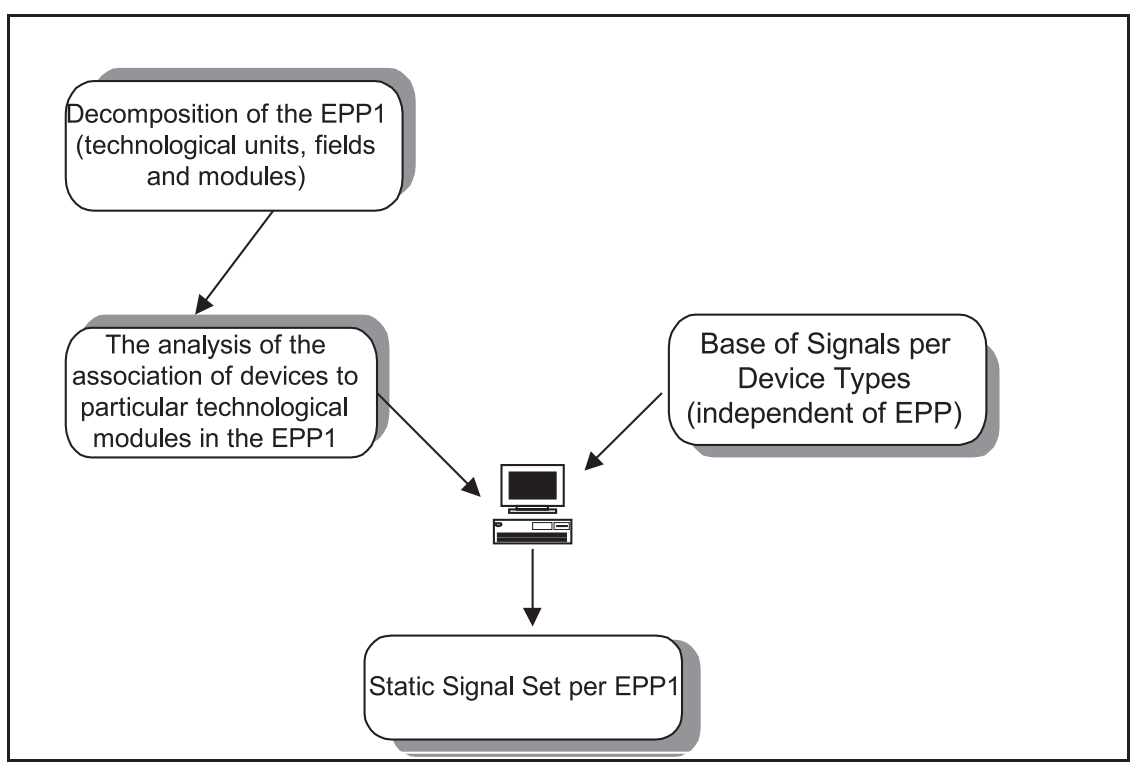

Fig. 9. Procedure for generating set of static signals per EPP. 


\begin{tabular}{|c|c|c|c|}
\hline EPP SENJ & 35 kV FB Senj & feeder disconnector - command & connect \\
\hline EPP SENJ & $35 \mathrm{kV} \mathrm{FB} \mathrm{Senj}$ & feeder disconnector - command & disconnect \\
\hline EPP SENJ & $35 \mathrm{kV}$ FB Senj & feeder disconnector & connect \\
\hline EPP SENJ & $35 \mathrm{kV} \mathrm{FB} \mathrm{Senj}$ & feeder disconnector & disconnect \\
\hline EPP SENJ & 35 kV FB Senj & feeder disconnector & intermediate position \\
\hline EPP SENJ & 35 kV FB Senj & feeder disconnector & failure \\
\hline EPP SENJ & $35 \mathrm{kV} \mathrm{FB} \mathrm{Rab}$ & feeder disconnector - command & connect \\
\hline EPP SENJ & $35 \mathrm{kV}$ FB Rab & feeder disconnector - command & disconnect \\
\hline EPP SENJ & 35 kV FB Rab & feeder disconnector & connect \\
\hline EPP SENJ & $35 \mathrm{kV} \mathrm{FB} \mathrm{Rab}$ & feeder disconnector & disconnect \\
\hline EPP SENJ & $35 \mathrm{kV} \mathrm{FB} \mathrm{Rab}$ & feeder disconnector & intermediate position \\
\hline EPP SENJ & 35 kV FB Rab & feeder disconnector & failure \\
\hline EPP SENJ & $35 \mathrm{kV} \mathrm{FB} \mathrm{Senj}$ & I> protection starting & OK \\
\hline EPP SENJ & 35 kV FB Senj & I> protection starting & operating \\
\hline EPP SENJ & $35 \mathrm{kV}$ FB Senj & I> protection supply condition & OK \\
\hline EPP SENJ & $35 \mathrm{kV} \mathrm{FB} \mathrm{Senj}$ & I> protection supply condition & operating \\
\hline EPP SENJ & 35 kV FB Senj & I $>$ protection timing & $\mathrm{OK}$ \\
\hline EPP SENJ & 35 kV FB Senj & I $>$ protection timing & operating \\
\hline EPP SENJ & $35 \mathrm{kV}$ FB Senj & I $>$ protection highcurrent & $\mathrm{OK}$ \\
\hline EPP SENJ & 35 kV FB Senj & I $>$ protection highcurrent & operating \\
\hline
\end{tabular}

Table 6. Printout of the set of static signals.

and turbine engine splitting (TE). In addition to these usage locations, we have to point out two remote signal usage locations: Regional Control Center (RC) and National Control Center (NCC). Table 6 shows EPP signals and their usage locations. By defining Table 7, we have completed the EPP process signal designing.

At the end, it can be concluded that proposed device-based EPP modeling has to be done in three phases:
- the result of the first phase is a generic set of process signals per devices;

- the result of the second phase is concrete set of process signals at the EPP level;

- in the third phase, usage locations of every single signal should be determined.

\begin{tabular}{||l||c|c|c|c|c|c|c|c|c|c||}
\hline \hline \multicolumn{1}{|c|}{ EPP Signals } & EB & EA & AB & TE & CB & AS & RB & oth & RC & NCC \\
\hline \hline EPP_FB Senj 35kV_feeder disconnector - state_intermediate position & & & & & & + & & & + & + \\
\hline EPP_FB Senj 35kV_feeder disconnector - state_connected & & & & & & + & & & + & + \\
\hline EPP_FB Senj 35kV_feeder disconnector - state_disconnected & & & & & & + & & & + & + \\
\hline EPP_FB Senj 35kV_feeder disconnector - state_failure & & & & & & + & & & + & + \\
\hline$\cdots$ & & & & & & & & & & \\
\hline EPP_Turbine 1_elektrovalve_position_cooling water_operating & & + & & + & & & & + & + & \\
\hline EPP_Turbine 1_elektrovalve position_cooling water_restraint & & + & & + & & & & + & + & \\
$\cdots$ & & & & & & & & \\
\hline EPP_Generator 1_DC voltage_ok & + & & & & & & & + & + \\
\hline EPP_Generator 1_DC voltage_loss & + & & & & & & + & + \\
\hline$\cdots$ & & & & & & & \\
\hline \hline
\end{tabular}

Table 7. Presentation of one pattern of EPP signals per usage locations. 


\section{The Object-Oriented Characteristics of Device-Based Modeling}

In the previous chapter, device-based information model of the EPP is described. The core of the model are the devices arranged within technological EPP modules. The devices send and receive various signals. Such modeling is based on device abstractions and it can be applied in information modeling of any type of EPP. Functional modeling elaborated in Chapter 2 does not offer such flexibility.

In this chapter we want to underline and explain one important characteristic of devicebased modeling: modeling based on the devices in the very essence represents an object oriented view of the EPP, i. e. its parts. The following describes how to supplement devicebased model described in the previous chapter so as to become object model. Objectoriented modeling, nowadays, is considered to be a very qualitative and effective approach to system modeling. Moreover, it is supported by many modeling languages and tools. Therefore, our effort to define principles for mapping the device-based model to the object-oriented one is quite comprehensible [3], [9], [11].

\subsection{Analogy Between Device-Based and Object-Oriented Model}

The object model is based on the following concepts: object, object type, attribute, signal, state, operation, and behavior [1], [2], [5], [10]. Object is a concrete phenomenon of some abstraction. It is a basic entity in the object model with good determined borders and identity. The object encapsulates state and behavior. It is also an instance of some type of objects. In an EPP, devices represent sources of information. Some of them are also controllable elements in the EPP and are responsible for some behavior. Consequently, the most important objects in object-oriented information model of an EPP represent abstractions of real devices. These objects represent abstractions of technical devices actually placed in an EPP.

Object identity can be defined by its location in the EPP and following the technological decomposition described in 3.2. (Figure 8.). For example, object identifier which represents abstraction of feeder disconnector (FD) connected with $110 \mathrm{kV}$ busbar number 1 in feeder bay Melina of the hydro-electric power plant Senj, has the structure: HESenj.110kV.FBMelina.FD1. Generally, a device-representing object in EPP has the identifier of the structure:

EPP.VoltageLevelID.TechnologicalModulesID. DeviceID.

In a definite moment of time an object is in a certain state. During all its existence the object satisfies some conditions (feeder disconnector is connected) performs some activity (feeder disconnector is being connected) or expects some event (feeder disconnector has just received the signal Disconnect). The object state is defined by momentary value of its state variables i. e. attributes. The object state depends also on the state of some other object if the connection between them exists. In the EPP, there is very often an association between disconnector and circuit breaker. Accordingly, apart from its basic states: Connected, Disconnected and Intermediate position and depending on the state of associated breaker, the disconnector can also be in the state Blocked. For example, a simple abstraction of the device feeder disconnector can result in an object type Feeder Disconnector with one attribute: Position. The attribute can assume discrete values: Connected, Disconnected and Intermediate.

Apart form being in some state, an object is responsible for certain behavior. Behavior of the object is everything that can be registered and is a result of some event (signal, elapse of time, change of state or a demand for a certain operation). Operation represents a service incorporated into the object. This service can be required form the object of some specific type by which a specific behavior is provoked. For example, we can require connection of the objects of the Feeder Disconnector type by requesting the operation Connect().

In object-oriented model representing some EPP, the most frequent events are the object state change and signal appearance. The appearance (sending) of the signal is therefore a sort of event. The signal is interchanged between the objects, of which one represents sender of the signals e. g. a device object, and the other represents receiver of the signals e. g. usage location object. For example, the object of the 


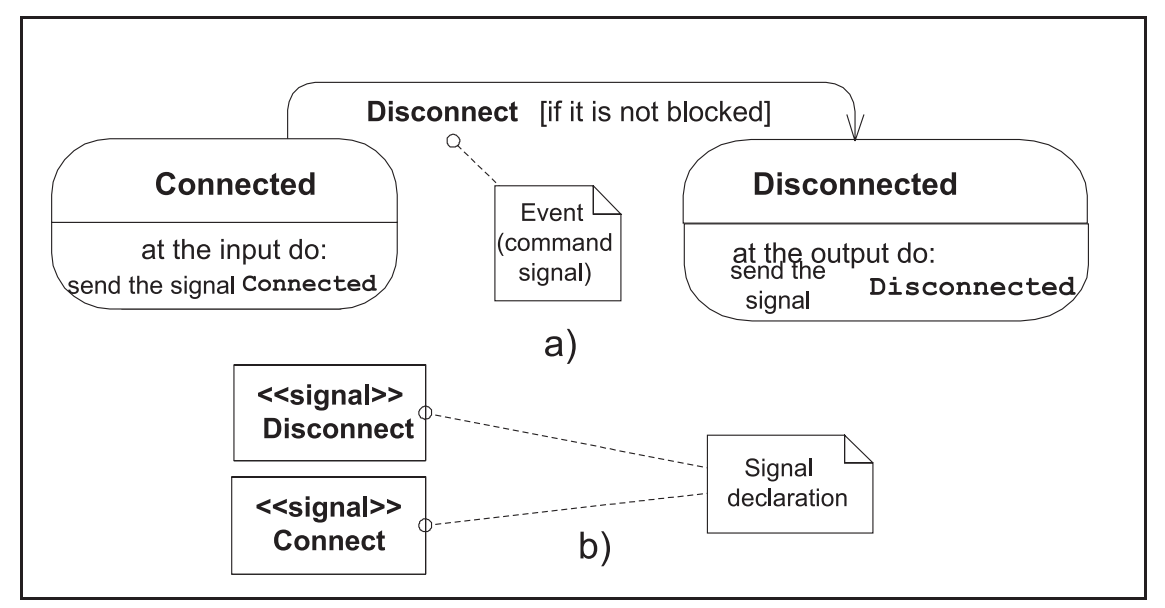

Fig. 10. Part of the state diagram of the Feeder Disconnector type.

Feeder Disconnector type can receive the signal Disconnect from the controlling object. A controlling object is an abstraction of one part of the system to control the EPP. This signal will provoke state change of the feeder disconnector if it is in the state Connected. Having changed from the state Connected into Disconnected, the feeder disconnector will send the state change information signal to the controlling object. This behavior can be illustrated by state diagram (Figure 10.a). In an objectoriented model, even the signal is treated as the object, the instance from the definite signal type (see Figure 10.b) which is mutually exchanged between object couple sender - receiver.

The concept object type represents a set of the same sort of objects which share the same attributes, operations and associations with other objects.

Finally, analogy between the concepts of the device-based and object-oriented models of an EPP is illustrated in Table 8.

\subsection{Object-Oriented Modeling Strategy}

Basic steps toward object-oriented EPP modeling are presented in Figure 11. The first step "finding of types and objects" is undertaken to identify objects as technical device abstractions which preserve their characteristics of technical devices as such, regardless of their function in the EPP, but with regard to information and process characteristics by which the EPP operation is described.

The second step is undertaken to identify structures of the types: generalization - specialization $(\mathrm{G}-\mathrm{S})$ Figure 12.a) and the type: whole part $(\mathrm{W}-\mathrm{P})$, Figure 12.b).

Defining relevant attributes means identification of and giving names to relevant characteristics of devices. Attribute values depend on its type. Attribute type in the model is specified

\begin{tabular}{|c|c|}
\hline Device-based modeling concepts & Object-oriented modeling concepts \\
\hline \hline device & object \\
\hline device type & type \\
\hline variable & attribute \\
\hline variable values & attribute values \\
\hline signal per device & signal \\
\hline signal per EPP & signal \\
\hline device state & object state \\
\hline command & operation \\
\hline signal usage location & signal receiver (object) \\
\hline
\end{tabular}

Table 8. Device-based modeling concepts and analog object-oriented modeling concepts. 


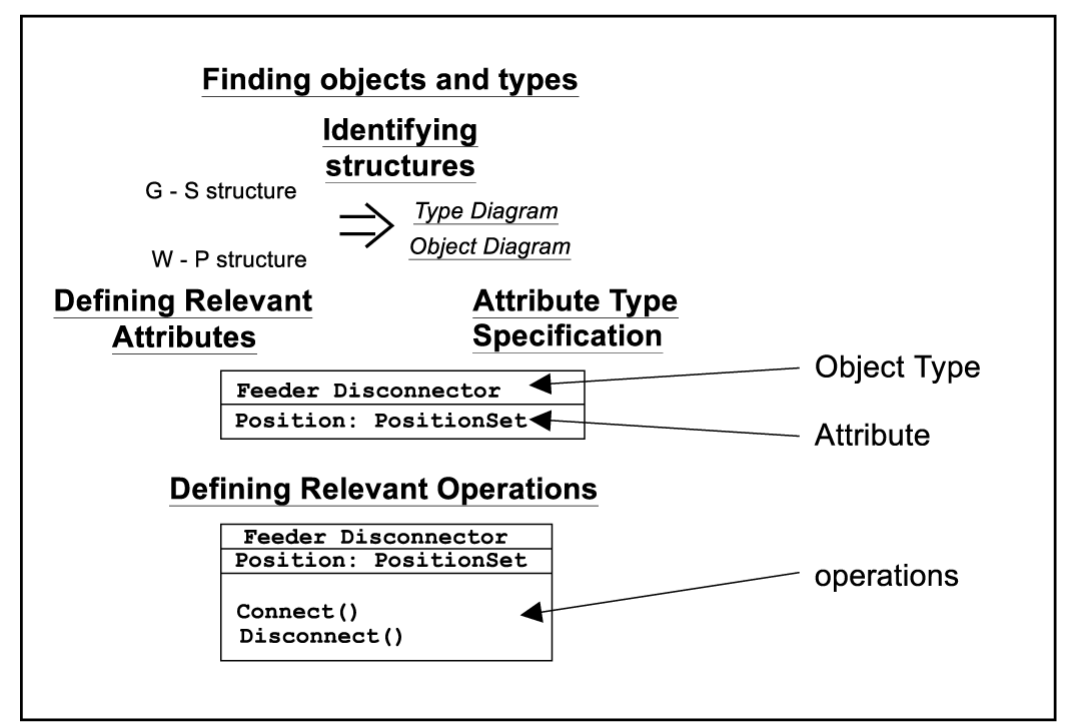

Fig. 11. Object-oriented EPP modeling strategy.

by some standard notation system. Relevant operations are the services offered by an object to its environment. The focus is here on external methods perceptible to surrounding object in the system. External operations represent signal specifications which can be directed to the respective objects. For example, an object of the type Feeder Disconnector can receive the following signals:

\section{HESenj.110kV.FBMelina.FD1.Connect}

\section{HESenj.110kV.FBMelina.FD1.Disconnect}

State change signals transmitted to controlling objects after the change of state, can be specified in the context of the state diagram elaborated for each object type separately. In Figure 10.a) only a part of the state diagram of the class Feeder Disconnector is shown. Complete state diagram should specify the minimum of three state change signals:

\section{HESenj.110kV.FBMelina.FD1.Connected}

\section{HESenj.110kV.FBMelina.FD1.Disconnected}

HESenj.110kV.FBMelina.FD1.IntermediatePosition

The examples elaborated in this chapter have illustrated the most important aspects relevant for relating the object modeling to the device-based EPP process signal modeling strategy.

\section{Conclusion}

Efficient and high-quality designing of the EPP automation and control systems was a real challenge during the nineties and has been ever since. The problem of process signal base specification is a significant design problem which can be resolved by using adequate information modeling technique. An efficient approach to the EPP information modeling can significantly

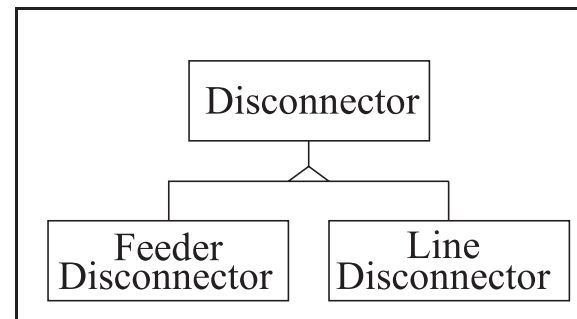

a)

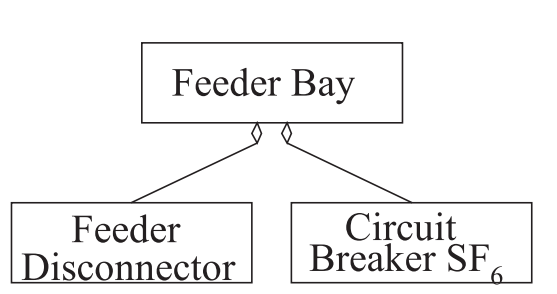

b)

Fig. 12. Generalization-specialization and whole-part structure. 
improve the process of automation and development of the control system design.

Proposed device-based process signal modeling offers a modular solution which enables efficient, rational and open possibility to organize a process signal base. The previously used functional design has some specific limitations, because a model can be defined only for one EPP and it cannot modularly and openly describe a larger system with more than one EPP. The device is not separated as an information bearing unit and device states cannot be defined for the needs of modern process signals design. Redundancy of the data entry is significant. The device-based design of a process signal base is, on the contrary, modular and open for describing a large number of EPPs, which is based on unique process signal base and it can be efficiently supplemented accordingly to the changes of primary process equipment. It is based on the device as the main information bearing and organizational unit. Besides the modularity, it can also be very easily mapped into the modern object- oriented model. The strength of object-models opens entirely new possibilities for EPP information modeling as well as for improving automation and control system design process.

Therefore, focus of the study will be on the further improvement of the described objectoriented modeling and also on development of a tool for both EPP modeling and automatic process signal sets generating.

\section{References}

[1] G. Booch, ET AL., The Unified Modeling Language User Guide, Addison-Wesley publishing company, Santa Clara, California, USA, 1998.

[2] G. Booch, Object - oriented analysis and design with applications, Addison-Wesley publishing company, Santa Clara, California, USA, 1997.

[3] M. RANDIC, ET AL., Information Modeling of Power Substations by Using Modeling Language, 10th Mediterranean Electrotechnical Conference MELEKON 2000, Lemesos, Cyprus, 2000.

[4] J. SimunIC, ET AL., Object-oriented Approach to Analysis in Power Substation Control, PSAC Symposium, Bled, Slovenia, October 1997.

[5] J. RuMBaugh, ET AL., Object-Oriented Modeling and Design, Prentice-Hall, Inc., New Jersey, 1991.
[6] J. Simunic, Z. Durovic, Basic Design of Process Information Flow in Electric Power Substation, Korema, 37-39, Opatija, 1996.

[7] J. SIMUNIC, MSSI - Modular Structure of stochastic Process Information for Power System Control, CIT, 4(3), (1978), 279-290.

[8] J. SimunIC, Electric Power System Analysis Using Modular Information Structure, Energija, 1-2, (1994), 39-51

[9] J. Simunic, ET AL., Object-oriented Information Modeling of Power Substations, Daaam, 22-24th October, Cluj - Napoca, Romania, 1998.

[10] B. F. Webster, Pitfals of Object-Oriented Development, M\&T Books, New York, 1995.

Received: May, 1999 Revised: November, 2000 Accepted: February, 2001

Contact address:
Marijana Zivic
Young assistant
Technical faculty
University of Rijeka
Vukovarska 58
51000 Rijeka
Croatia
Phone: +38551651438
Fax: +38551675818
e-mail: marijana.zivic@rijeka.riteh.hr

JURAJ SIMUNIC is Assistant Professor at the Technical Faculty, University of Rijeka. For seventeen years he has been working for "Hrvatska elektroprivreda" as an expert in planning, operation and control of power system. He concentrates on modeling of stochastic process information flow in power systems. This was the subject of his doctoral thesis upon which he received his Ph. D. in 1991. from the Faculty of Electrical Engineering and Computing, University of Zagreb.

MIRKO RANDIĆ was born in Croatia in 1962. He received the M. S and $\mathrm{Ph}$. D. degrees (both in Electrical Engineering) from the Faculty of electrical engineering and Computing, University of Zagreb. Currently he is Assistant at the same faculty (Department of Electrical Fundamentals and Measurement). His research interests include object-oriented modeling, formal specification techniques and ORB-centric software modeling.

MARIJANA ZIVIC was born in Slavonski Brod in 1972. She received her B. Sc. degree in electrical engineering from the Faculty of Electrical Engineering and Computing, University of Zagreb in 1996. In the same year she became a staff member of the Technical Faculty, University of Rijeka as a younger assistant. Her present research interests focus on the signal processing. 